Article

\title{
From Disability Rights to the Rights of the Dying (and Back Again)
}

\author{
Harold Braswell \\ Albert Gnaegi Center for Health Care Ethics, Saint Louis University, St. Louis, MO 63104, USA; \\ harold.braswell@slu.edu
}

Received: 14 August 2017; Accepted: 11 December 2017; Published: 15 December 2017

\begin{abstract}
This article argues for civil rights for dying people. The creation of such rights should be understood as complementary to, but distinct from, existing initiatives to provide dying people with social benefits. A basis for rights for terminally ill people can be found in the disability rights movement. Through an ethnographic case study of two dying individuals, I argue that terminally ill people can be subjected to disability discrimination as it is understood within the dominant theoretical framework of disability rights: the social model of disability. Nevertheless, while disability rights provides a theoretical basis for understanding discrimination against people who are dying, existing U.S. disability rights legislation largely does not recognize, nor address this discrimination. For this reason, it is necessary to develop a separate set of rights of the dying. I conclude by arguing that such "dying rights" are a logical extension of disability rights, and will bring ancillary benefits to both disabled people and the disability rights movement itself. There is thus a strong foundation for a legal and political alliance between disability rights advocates and advocates for people who are dying.
\end{abstract}

Keywords: disability rights; terminal illness; death and dying; ethnography; civil rights; bioethics; physician-assisted suicide

\section{Introduction}

This article argues for civil rights for dying people. By "dying people", I mean people who have been given a medical prognosis of six months or less to live. Though contestable, this definition is standard in the health policy and law of the United States, the country in which my argument is set (Lynn et al. 1996). This argument builds on Bruce Jennings' recent call for a "public" approach to end-of-life care (Jennings 2013, p. 272). Such an approach would not understand "inadequate" care as an issue that is primarily "personal" or "familial." It would be considered a product of a "failing civic system of health care and communal provision" (Jennings 2013, p. 273). Ameliorating it requires the development of what Jennings calls "civic palliative care". Such care creates "a social and cultural lifeworld" for terminally ill people (Jennings 2013, p. 275). This "public" framing is, according to Jennings, better suited to identify the resources needed by the dying, and to articulate ethical justifications for their provision.

The present article extends Jennings' vision. In it, I argue that law can play a central role in the development of such "public" end-of-life care. It can do so through the articulation of civil rights for the dying. Such rights would understand "terminally ill" people to be a protected class that can be subjected to discrimination. These rights would also enjoin the state to provide dying people with resources, not based on welfare, but because they are entitled to them as citizens. Such rights are not a substitute for the rich communal networks that Jennings prescribes. However, they can provide an essential context for such networks to exist. Indeed, the lack of such rights can, I argue, be a central cause of "inadequacies" of the sort that Jennings identifies. 
I make this argument through a study of end-of-life care in the United States. First, I will show how the lack of a civil rights movement has facilitated the creation of a U.S. hospice system that is both underfunded and inadequate in its provision of care. Though a civil rights approach will not be a panacea, it allows for the articulation of stronger claims regarding the obligation of the state to provide resources for dying people. However, though U.S. end-of-life care might suffer for the lack of a civil rights movement for dying people, this in itself is not sufficient grounds to examine whether such a movement should exist. To do so, it is necessary to consider what kind of specific civil rights laws might apply to the dying.

A good model for such laws is, I argue, disability rights. Disability rights, through their basis in the "social model of disability", provide a potential theoretical framework through which we might understand dying people as vulnerable to discrimination. To explore whether this framework can be applied to the dying, I present an ethnographic case study of two patients dying in U.S. hospice care. I argue that both of these patients can, and should, be understood as victims of discrimination as defined by the social model of disability and, more specifically, well-established disability rights. A disability rights framework thus provides a feasible starting point for the elaboration of a "rights of the dying".

The same cannot be said, however, of most existing U.S. disability rights legislation. Although terminally ill people can be subjected to discrimination, as understood within a "social model", the particular form that this discrimination takes can be very different than discrimination leveled at disabled people. For this reason, existing U.S. disability rights legislation is of limited use in addressing the needs of the dying. I show this through an analysis of the applicability of the Americans with Disabilities Act (ADA) to terminally ill people. The limits of the ADA in addressing discrimination against the dying provides a justification for the creation of a distinct piece of civil rights legislation on their behalf.

I conclude, rather, by arguing that such "rights of the dying" are consonant with the goals of the disability rights movement, and, as such, they should be supported by disability rights advocates. Such support should not solely be based on shared philosophical premises. Though primarily targeted at terminally ill people, rights for the dying will likely have significant ancillary benefits for disabled people. Furthermore, an alliance between disability rights advocates and advocates for the dying will help garner the political capital necessary to advance causes that benefit both dying people and disabled people. In this sense, the rights of the dying represent a more complete realization of the project of disability rights itself.

Though the case studies in this article are set in the U.S., my theoretical framework and, more broadly, the political alliance I recommend would apply across national borders. Before I can articulate the rationale for such an alliance, I must begin by addressing the issue that, more than any other, has halted its emergence: physician-assisted suicide (PAS).

\section{Why This Article Is Not about Physician-Assisted Suicide}

PAS has dominated interaction between disability rights advocates and advocates for dying people (for recent examples of this interaction see (Davis 2013; Gill 2010; Neumann 2016)). To an extent, this domination is understandable: PAS is an important issue both in general and, specifically, for disabled people, even in a country such as the U.S., where the practice is limited only to the terminally ill. However, it is also unfortunate.

Discussions of the relationship between disability rights advocates and advocates for PAS generally center on the conflict between these two groups. There is a substantial conflict-as has been argued forcefully by scholars such as Carol Gill and Paul Longmore-and it is worth discussing (Gill 1998; Longmore 2005). However, this conflict is not the only way to imagine the relationship between the two constituencies putatively represented by "disability rights" and PAS: the long-term disabled and the terminally ill. As I hope to show here, there are substantial intersections between dying people and disabled people that have nothing to do with PAS. Such intersections represent 
points of alliance, and productive opportunities to rethink the relationship between these two groups. Yet, such opportunities are lost if the focus is limited to PAS.

PAS would not, in theory, have to be the "focus" of an article exploring the relationship between disability rights and the rights of the dying. However, in practice, it almost certainly would be. In part, this is because the enormous amount of attention the issue has received over the past two decades has likely conditioned readers to ascribe to it an importance that—as Ira Byock has recently argued-it may not deserve (Byock 2012, pp. 272-96). But it is also because, even after these two decades, there are still significant disagreements on whether PAS should be considered a legitimate right at all. These disagreements are worthwhile, and I address them elsewhere (Braswell 2018). But, however one resolves them, it is likely to alienate a substantial group of people who, except for PAS, might agree with the framework for conceptualizing the relationship between terminal illness and disability that I develop here.

This framework is, I believe, of greater importance than the issue of PAS itself. Even if one supports PAS, that does not mean that it should be considered the primary, much less the only, right of the dying. In this respect, advocates for the dying can learn a great deal from advocates for disability rights. There are disability rights advocates who support legalizing PAS (Batavia 1997; Behuniak 2011; Davis 2013). Such advocates argue that PAS is a logical extension of disability rights. They do not argue, however, that PAS could conceivably replace disability rights.

And yet, this is where we are with regard to the "rights of the dying." For (at least) the past two decades, there have been repeated debates about PAS for terminally ill people (Dowbiggin 2007). However, these debates have come prior to the establishment of significant laws to protect the dying from discrimination. There are valid justifications for why PAS might be given greater prominence in discussions of terminal illness than it is in long-term disability: the increased severity of medical conditions, the significantly heightened proximity to death. However, these reasons cannot justify the almost complete opposition between how the issue has been framed in these two populations.

Dying people and disabled people are different. However, they are not opposed in every fashion. They do, as I will show here, have shared interests, and shared enemies. PAS can figure into conversations about such communalities, but it need not do so, and cannot be the primary point of entry. By setting it aside-for the time being-I hope to create an opening for something new. I will now explain why that "something" is necessary in the United States.

\section{The Limits of a Social Benefits Approach}

In the United States, federal legislation for dying people has generally not taken the form of civil rights. Instead, federal legislation for the dying has generally adhered to a "social benefits" model (on social benefits in the U.S., see (Hacker 2002)). Such benefits are not considered to be legal obligations essential to the freedom of their recipients from discrimination. Rather, they are understood through the lens of charitable beneficence and, in a kind of paradox, efficient economic management. To understand this paradox-and its effect on terminally people-it is necessary to consider the signature piece of federal legislation for people who are dying: the Medicare Hospice Benefit (MHB).

Prior to the Medicare Hospice Benefit, "hospice" in the U.S. was a grassroots movement that lacked a uniform structure outside of its general meaning of "care for the dying" (Paradis and Cummings 1986). The very meaning of "hospice" varied from state to state, even hospice to hospice, as did the kinds of care that would be included under the "hospice" label. This decentralized structure was itself a product of the lack of any standardized reimbursement mechanism for hospice services. Different hospices had to work within different reimbursement mechanisms, and these mechanisms influenced their own local conception of hospice care (Hoyer 1998; Paradis and Cummings 1986). It is thus debatable whether there was a uniform U.S. definition of hospice prior to the MHB's passage in 1982.

The MHB changed this situation by providing a reimbursement mechanism at the federal level. This reimbursement mechanism would pay for hospice. However, it would also define the very 
meaning of "hospice" itself. To receive Medicare reimbursement, hospices would have to comply with Medicare regulations. These regulations would require them to change their conceptions of care, in some ways dramatically (as I will explain further below). Thus, by creating a federal reimbursement structure, the MHB created a uniform national definition of "hospice". Decisions about what would be included-or excluded-from this definition were shaped by the priorities of the congressional legislators who supported the benefit. These legislators were motivated by two principal justifications: one clinical, one economic.

Clinically, there was a growing recognition of the inappropriate and even harmful nature of much U.S. care for the dying (Abel 2013, 2017). Dying Americans were either treated as if they were curable, in hospitals; or they were treated as if they were chronically disabled, and sent to nursing homes. Neither institution was appropriate to their needs.

This clinical justification was accompanied by an economic one. Hospital and nursing home care of the dying were extremely expensive. The government carried much of the cost of this care through Medicare and Medicaid. U.S. hospice leaders argued that hospice would reduce the cost of care relative to these other treatment modalities. These claims were, to a degree, confirmed by a number of studies (Kidder 1992; Mor and Kidder 1985). It thus seemed that funding hospice would both save the government money and provide the dying with better care.

In theory, it is possible such an arrangement could work. However, it does pose a potential conflict: at what point does the need to save money endanger the proposed clinical benefits? There is strong evidence that, at the time of the MHB's passage, U.S. hospice leaders were aware of such a possibility, and indeed believed that it was inherent to the MHB itself. As Emily Abel has found, U.S. hospice leaders at the time believed the MHB's reimbursement rate to be "far too low" (Abel 2017, p. 126). The result would set up a structure in which individual hospices would have to choose between providing appropriate care, from a clinical perspective, and remaining financially solvent, not to mention profitable. There is ample evidence that this conflict between cost and care remains present-and has even worsened—in hospice today (Halabi 2014; Perry and Stone 2011).

This conflict shaped not only how much the Benefit paid for its services; it also influenced what services were included in it at all. The Medicare Hospice Benefit does not include comprehensive long-term care. Such long-term care includes assistance with activities of daily living, such as feeding, clothing, and basic hygiene. As long-term care is expensive (Institute of Medicine 2014, p. 296), this lack of long-term care coverage significantly reduced the benefit's cost on the government. However, it created a clinical gap: terminally ill patients are highly disabled and, as such, have significant long-term health needs.

This raises a question: who provides dying Americans with long-term care? The U.S. hospice system is designed for such care to be provided by the patient's primary caregiver, a person who, in hospice literature, is frequently considered to be a member of their "family" (a term that in this case does not require biological relation) (Rabow et al. 2004). Such familial caregivers are not reimbursed, by Medicare, for their services. As such, the Medicare Hospice Benefit, while providing some support for the dying, itself gives a significant amount of the burden of end-of-life care to the family (Institute of Medicine 2014, p. 297). This dependence on the family is largely a result of the Benefit's cost-savings function. However, it creates clinical problems for the dying.

Dying patients have extremely significant medical conditions, indeed, arguably the most significant medical conditions imaginable. However, the MHB's structure is premised on care being provided to these individuals by family members who often lack basic knowledge in medication management (Institute of Medicine 2014, p. 311). In addition, a number of sociological factors-lowering birth rates, rising divorce-have made it so that many Americans do not have family members available to care for them (Levitsky 2014). Even when a person does have family, the lack of paid familial leave in the U.S. makes it extremely difficult for family members to obtain leave from work sufficiently to care for their kin (Levitsky 2014, p. 26). Even when a person has the financial resources to provide care, there are other barriers, including caregiver disabilities, interpersonal conflict, 
and negative "neighborhood effects" that can impede family caregivers from providing appropriate care (Levitsky 2014; Sampson 2012). The result is a significant gap between the abilities of caregivers and the requirements of the MHB. This gap can lead dying patients, in the home context, to suffer significant neglect, and even abuse, and, more generally, can lead to dramatic instability in care delivery (Institute of Medicine 2014, p. 281).

When a suitable familial caregiver is not available, dying individuals are generally sent to nursing homes. Nursing homes are institutions that provide long-term care. They do so, in general, for a population that is long-term disabled. However, they also provide long-term care to dying patients who cannot remain at home. Such patients continue to receive hospice, which is provided on an outpatient basis. But though, under Medicare rules, hospice patients cannot receive "skilled" nursing care-complex medical interventions designed for disabled people-they may be housed in facilities that provide it. These facilities have a financial incentive to "skill" patients, and they may also believe it to be clinically necessary, since dying people can benefit from skilled care. However, because of the way the MHB is structured, providing them with such care requires removing them from hospice. The result generates an inherent tension between hospice and nursing home providers that can lead to the unnecessary discharge of dying patients from hospice (Aragon et al. 2012; Institute of Medicine 2014, p. 297). Finally, the high rate of turnover in nursing home staff itself presents a barrier to care in general and the delivery of hospice in particular (Stevenson and Bramson 2009). As a result, there are significant-and perhaps systemic-difficulties in coordinating hospice and nursing home care (Aragon et al. 2012).

The lack of long-term care in the Medicare Hospice Benefit thus creates a barrier to the delivery of care both at home and in the nursing home context. At the time the MHB was passed, hospice advocates knew about this problem and testified to Congress on the need for significantly more inpatient, long-term end-of-life care (The Connecticut Hospice 1982). Their protests went unheeded then and the problem has arguably gotten worse over the following 30 years.

The conflict between the MHB's economic rationale and its clinical one has significantly hampered the efficiency of hospice care. This inefficiency has been noted by the recent Institute of Medicine report on the state of U.S. end-of-life care, which recommends that a "major reorientation of Medicare and Medicaid is needed ... to address the central needs of nearly all Americans nearing the end-of-life" (Institute of Medicine 2014, p. 266). Given the cost of such reorientation, it is unlikely to happen in a legislative context that remains focused on reducing the cost of government expenditures in general and, more particularly, at the end-of-life (often exaggerating the cost of end-of-life care in the process) (Aldridge and Kelley 2015). Ameliorating this problem requires finding a new way to approach the care of the dying that is not predicated on a tradeoff between clinical care and cost-savings. Such an approach can be found in civil rights.

\section{The Benefits of a Civil Rights Approach}

Discussing the disability rights movement, Andrew Batavia and Kay Schriner articulate the benefits of taking a "civil rights" approach to improving the well-being of disabled people:

[C]ivil rights laws have not been subject to the strict budgetary and regulatory restraints of other types of legislation for people with disabilities. There is a recognition that, because civil rights are fundamental to justice, once they are recognized they must be provided largely irrespective of cost. Congress and the implementing agencies may determine and impose the most cost-effective means of ensuring the right, but cannot deny the right due exclusively to the costs (Batavia and Schriner 2001, p. 696).

A civil rights model thus provides a different framework for understanding government expenditures than a social benefits approach. Within hospice, essential services were arguably denied, to a great extent, solely on the grounds of cost. Reframing the provision of such services as a right would obviate this argument. 
It is important not to overstate the importance of this contrast: as the history of the ADA shows, civil rights can be significantly curbed, if not outright denied, on the basis of costs (Krieger 2003). Additionally, a civil rights approach can be limiting in manners that a social benefits approach is not; indeed, many current disability advocates are now arguing in favor of adopting social benefits approaches much like the MHB (Bagenstos 2009, pp. 131-50; Schriner and Scotch 2003, pp. 183-84). My argument here is not that a civil rights approach to the dying is inherently superior to a social benefits approach. However, it does open up new ways of recognizing and remedying the significant problems facing the dying in America.

Writing about civil rights for the elderly, Nina Kohn has eloquently expressed the power of reframing as rights issues that were previously largely discussed in terms of charity or social benefits:

[A] focus on rights is of significant value where the rights in question have not yet been recognized as such. In the context of elder rights, there has yet to emerge any meaningful, broad-based political agitation, and none is likely to emerge unless these political actors are aware of these problems and consider them to be important ones. By labeling and describing these problems as ones that threaten rights, and especially ones that threaten constitutional rights, a rights-based approach can both bring needed attention to them and elevate their perceived importance. As such, it is not an alternative to a political strategy, but potentially a prerequisite for one (Kohn 2010, p. 76).

The same is true of rights for the dying, a group that, like the elderly, has not generally had their concerns (aside from physician-assisted suicide) framed in legal or even political terms. Through such a reframing, the "rights of the dying" will provide additional leverage to resolve some of the major problems that we already know exist in U.S. end-of-life care, and perhaps an additional ability to identify some problems that are, for now, not even recognized at all.

But beyond even its instrumental value with regard to particular issues, a rights-based reframing can create a powerful political network that extends from dying individuals to those that care about them throughout American society. The creation of such a network can be valuable in itself, cultivating what Jennings, in his essay on civic palliative care, refers to as "solidarity", which is based in the "discernment of connections among human beings that are obscured by structures of wealth, power, and privilege" (Jennings 2013, p. 280). Such solidarity can be a source of immense comfort, particularly in cases where individuals experience extreme isolation, as is, unfortunately, the case with a significant portion of the dying.

While intrinsically valuable, solidarity can in turn also have instrumental value beyond the ambit of rights. Networks of solidarity created, in part, by civil rights can be mobilized in the service of organizing for more social benefits, even if those benefits themselves do not depend on civil rights. In this sense, while it is important to recognize the limits of rights in general, and anti-discrimination law in particular, rights have immense power both within the law and beyond it. A civil rights approach to the dying will not solve all our problems. However, when joined with the existing social benefits approach, it will provide a much more promising starting place.

But however useful a civil rights approach might be, it cannot solely be justified by the inefficiencies in U.S. hospice care delivery that I have outlined above. Such inefficiencies need to be reframed and identified as violations of fundamental rights. Here we come to a problem: how can we identify that the rights of the dying are being violated if there has not yet been a movement to establish such rights?

It is here that the disability rights movement can be of such help. Terminally ill people are highly disabled (Lunney et al. 2003). As such, they may be subject to disability rights. However, that is not necessarily the case. To establish whether or not a particular population might be protected under disability rights, it is not enough to show that they are disabled. It is necessary to demonstrate that they experience disability discrimination. And it is not necessarily true that terminally ill individuals experience such discrimination. Indeed, the assumption of disability rights advocates, in discussing terminally ill people, has often been that they do not. 
This assumption has underpinned both opposition to and support for physician-assisted suicide among the disability rights community. Disability rights opponents of PAS have worried that legalizing the practice will lead to the conflation of terminal illness and disability (Heyer 2011). Disability rights supporters of PAS have supported it, in part, on the grounds that terminally ill people have more significant medical conditions, which create a stronger argument for making PAS available to them (Batavia 1997; Davis 2013). Though some disability rights commentators have identified instances of disability discrimination against terminally ill people (Gill 2010), there has not been a sustained scholarly argument to that effect, nor any argument that extends beyond the highly limited context of the PAS.

Prior to any attempt to apply existing disability rights law to terminally ill people, it is first necessary to examine whether terminally ill people can be subjected to disability discrimination. I will now consider this question via an analysis of the situation of two terminally ill individuals who I studied as part of a larger ethnography of U.S. hospice care. I will refer to them as "Simon" and "Mary", and, in the interest of de-identification, I have changed several details of their identities.

\section{Simon and Mary}

Simon had lived the last twenty years of his life in California, largely by himself. However, when he was diagnosed with lung cancer, he realized that he would need help. So he moved: first to Florida to be with his ex-wife, then to Atlanta, Georgia to live with his brother. Simon began hospice service while at his brother's house, and at first it went well. But then his brother got a job as a flight attendant that required him to be out of town for long stretches of time. As a result, Simon was left home alone. Though he continued to receive hospice care, he spent most of his time unaccompanied.

In these circumstances, Simon became extremely isolated. He was too debilitated to drive, and his sprawling Atlanta suburb lacked access to public transportation, and was not readily walkable. His hospice providers came regularly, but still he dealt with untreated pain. His brother's house was inaccessible, and he fell several times. Due to these factors, he became depressed. He began sleeping for as much as twelve hours at a time, and stopped eating. This depression was in part caused by a general feeling that he described as "uselessness", and of being a burden on his already struggling brother.

Simon did not want to go to a nursing home. Having been in nursing homes before, he preferred to stay in his brother's house, even with the adverse and potentially life-threatening consequences. Ultimately, an alternative presented itself: Simon was able to move to a charitable Catholic facility that was up to his standards. In this home, he achieved a higher degree of social integration than had been available to him in his brother's house. His depression lifted and he outlived his prognosis by several months. However, this "solution" to Simon's isolation at home did not come from within the US hospice system. It came from escaping it.

Mary Bonner, in contrast to Simon, did pursue the "solution" that would have been available to Simon had he stayed within hospice. She was eighty-two years old, and had been admitted to hospice with Parkinson's disease and advanced dementia. This combination of dementia with Parkinson's had made it impossible for her husband—who was also in his early eighties—-to care for her. As a result, she had been placed in an Atlanta-area nursing home that I will refer to as "Sunny Day Nursing Home".

Though living in Sunny Day, Mary had family members that, though unable to care for her personally, were very supportive. The home was only five miles from her house, and her husband would visit her almost every evening. She also had several grandchildren living in the area, who would visit her two or three times a month. Most importantly, Mary had her son, who lived nearby, and who visited her several times a week. During these visits, Mary's son not only kept Mary company—serving as an invaluable connection between her life inside the nursing home and her life outside of it-but also advocated for her with both hospice and nursing home staff. Nevertheless, even this advocacy was insufficient to assure Mary the delivery of either adequate long-term or end-of-life care. 
Mary encountered repeated difficulties in receiving not only her pain medication, but also her dementia care. Over the coming weeks, the nursing home staff failed several times to provide her with her medications at regularly scheduled hours. This failure persisted despite the presence of Mary's son as a strong patient advocate. However, he was in a hard position. He had to hunt down nursing home personnel who seemed to change every other day, and who- even when consistent-were so busy that they did not have time to talk; at the same time, he had to talk by phone with hospice personnel who only visited his mother at Sunny Day around twice a week. The result was a process at once exhausting and futile. Mary endured untreated pain, and her son's final months with his mother were lost in bureaucracy.

While Mary was at Sunny Day, the nursing home had an outbreak of pneumonia. As a result of this outbreak, Mary became sick, as did several other patients in the home. Though she recovered from the pneumonia, the experience was traumatizing for both her and her son. In addition, she fell several times at the home. Though these falls only bruised her, these bruises were painful and-when coupled with her dementia and the nursing home's lack of skill with pain medication-they left Mary in a state of both pain and persistent confusion. In addition to this, she endured inadvertent, and likely unintentional, abuse from nursing home staff, who bruised her arms repeatedly while moving her. These questions of inadequate and abusive treatment were not resolved prior to Mary's eventual death.

Having the presented the cases of Simon and Mary, I will now analyze the extent to which they might justify a "disability rights" approach to terminal illness.

\section{The Applicability of a "Disability Rights" Approach to the Terminally Ill}

As I described above, the fundamental theoretical question, in determining whether a disability rights approach might be applied to terminally ill people, is whether or not terminally ill individuals experience disability discrimination. Such discrimination would be understood through the lens of the "social model" of disability. The social model of disability is best understood in contrast to what is referred to, in disability studies, as the "medical model" of disability (Shakespeare 2013). The social model and the medical model are distinct ways of understanding existing inequalities between disabled and non-disabled people. The medical model attributes these inequalities largely to the biological nature of disability; it argues that disability is an inherently negative condition, and that this negativity in large part accounts for the limited access that disabled people have to shared social resources. The social model, in contrast, argues that the negative aspects of disability are not, in general, inherent to its biology. They are products of a discriminatory society. This discrimination, not disability itself, is the reason for existing inequalities between disabled and non-disabled people and, moreover, for much of the suffering experienced by disabled people in general. The social model of disability thus reframes disabled people as a political group that can be-and frequently is—subject to discrimination.

From the perspective of the social model of disability, Simon and Mary both experienced disability discrimination. To be sure, both had extremely significant and limiting medical conditions. Simon's cancer was painful, and it limited his mobility significantly; Mary's Parkinson's and dementia were similarly limiting. But both individuals, in addition to these medical limitations, experienced significant social limitations as well. These social limitations are significant enough to justify a formulation of what might be called a "social model of terminal illness".

Simon was living in a house that was extremely inaccessible, and had in fact become physically, mentally, and emotionally dangerous to his well-being. This house, in turn, formed part of a local community that was itself largely inaccessible. As a result, he was effectively trapped within it. The result was physical injury, and an environmentally induced depression that significantly shortened his life expectancy. Very little of this situation can be described as "inherent" to his terminal illness. Social isolation is not a medical condition, and many of Simon's "medical" problems can in fact be attributed to a hospice system that repeatedly failed to provide him with appropriate medical and long-term care. The result was the effective segregation of him within his home. 
Simon's alternative to such home-based segregation was Mary's fate: segregation within an institution. Mary was living in—and died within-a nursing home. Such nursing homes have long been considered segregationist institutions from a disability rights perspective (Johnson 2003). If such a perspective can be applied to disabled people, it can also be applied to people who are terminally ill. Indeed, the argument against nursing homes, from the perspective of the dying, is arguably stronger. Nursing homes, however segregationist, are institutions designed for disabled people. They are not institutions for dying people. Dying individuals require significantly more medical care than would be provided in an "unskilled" nursing home, and significantly different care than would be provided in a "skilled" facility. Indeed, Mary's nursing home lacked the means to provide her with appropriate pain medication, dementia care, or even basic long-term care. Its workers were largely untrained in caring for a patient as sick as her, resulting in routine injuries and service failures. The result was a denial of care that significantly worsened her condition in a manner that was not "inherent" to her medical trajectory.

Thus, for both Simon and Mary, the only options available to them in the U.S. hospice system were segregated. This segregation occurred informally, in the home context, in the case of Simon. It occurred formally in Mary's placement in a nursing home. In both cases, neither individual had the basic resources to be integrated into society. This lack of integration, in turn, was both a product of, and a cause of, the harms that they suffered in each site. Though some of these harms might be attributable to their terminal diseases, a significant portion of them were due to the current arrangement of U.S. hospice care: specifically, in these cases, to the lack of long-term care in hospice.

In the preceding section of this article, I argued that this lack of long-term care is attributable, in part, to the lack of civil rights for dying people in America. The Medicare Hospice Benefit's character as social welfare, not civil rights, led to a conflict between clinical care and cost efficiency. This conflict led to the exclusion, from the very definition of "hospice", of features that U.S. hospice leaders deemed-and continue to deem-essential, such as long-term care. This section builds on that argument: the MHB's lack of long-term care was not only a creation of the lack of "rights" for the dying; it creates a situation - in the cases of Simon and Mary - where the dying can be housed in segregated environments that deprive them of what are, and should be considered, disability rights.

Ruth Colker's recent book When is Separate Unequal? provides a window into the extent of this problem. Colker argues that, at times, segregated institutions for disabled people may be justified from a disability rights perspective, as more integrated institutions may overlook the needs of those who are most disabled (Colker 2008). I am sympathetic to this argument. Indeed, to a degree, Simon's case might illustrate it. Simon was living in the "integrated" environment of the home. However, this home environment was so inadequate to his needs that it effectively resulted in his implicit segregation and neglect.

Compared to this home environment, the Catholic charitable facility that he spent his final months in was superior. Indeed, I would argue that this facility, though "segregated" in that it was designed for terminally ill people, was less segregated than Simon's home. The stability that he enjoyed there allowed him to have routine visitors, and arguably more fulfilling contact with these visitors than had previously been possible to him in his desperate situation. This is not to say that, even in Simon's case, such a separate facility should necessarily have been the first option. Better long-term care, better fall prevention: these are interventions that might have made it possible for Simon to remain at home.

My point here, rather, is that, in the U.S. hospice system, both the "segregated" and the "integrated" options available to Simon were effectively the same. It is thus telling that the only escape from such segregation, for Simon, was by leaving the hospice system altogether. The nursing home where Simon would have otherwise ended up would not likely have been a "separate but equal" facility for dying people. Indeed, the housing of dying people in nursing homes, if anything, illustrates Colker's critique of integration. By integrating dying people within a larger long-term disabled population, their needs are subsumed. 
The problem is that no such "separate but equal" institutions for dying people exist in the U.S. hospice system. There are isolated examples of them in U.S. society: homes run by religious charities, the "hospice home" movement (Wyatt 2015). But these examples are not systemic, and they in general operate through either private pay or charitable donations. The institutions that do exist within the U.S. hospice system are short-term: generally only for respite care or for patients with a few days to live. In addition, they are growing fewer and fewer, with only one in five U.S. hospices having such a facility (National Hospice and Palliative Care Organization 2012).

Thus, in both Simon and Mary's cases, there is evidence of disability discrimination against terminally ill people. Such discrimination is, in some ways, different than the disability discrimination experienced by long-term disabled people. Mary and Simon had more significant medical conditions than most long-term disabled individuals, and the resources they needed might be different than those that would be supplied under a standard "disability rights" framework. However, this difference is one of degree. It is possible to understand the state of terminally ill individuals from a disability rights perspective.

This raises another question: while, in theory, a disability rights framework can be applied to terminally ill people, how well might existing disability rights legislation work to provide them with civil rights? I will now examine this question, in the American context, by looking at the Americans with Disabilities Act.

\section{The ADA and Dying People}

The ADA is the landmark piece of civil rights legislation for disabled people in the United States. The Act identifies disabled people as victims of discrimination who needed specific state protection. To this extent, it was modeled on earlier civil rights legislation, particularly the Civil Rights Act of 1964 (Colker 2005, p. 17). However, the ADA goes beyond this legislation by postulating a state obligation to not only remove barriers to access, but also to provide the goods and services necessary for access to be achieved (though the extent of this divergence between the ADA and earlier civil rights legislation is debated) (Bagenstos 2009, pp. 10, 55-75). Though cost was a justification for the ADA-and certainly one that has figured prominently in the Act's interpretation-it was not the primary justification, and the Act has been at times interpreted in ways that establish a state obligation to go beyond what is strictly cost-effective (Batavia and Schriner 2001).

Similarly, though the Act provides benefits to disabled people, such benefits are not justified in terms of welfare or charity. In fact, the ADA is an explicit rejection of such charitable and welfarist models of disability (Scotch 2001). Rather, the justification of the ADA is the freedom of disabled people from discrimination. Though this justification has been limited by both concerns of cost, as well as those of what constitutes appropriate care, the ADA's fundamental basis in freedom makes such limitations legible and identifiable in a way that would not otherwise be possible (Batavia and Schriner 2001).

This freedom is interpreted, in the ADA, through the lens of the Act's three main titles. Title I establishes a right to "reasonable accommodation" in employment for disabled people (Americans with Disabilities Act 1991). This right is not proactive-employers do not have to design their businesses according to a model of universal design-but rather reactive, to be reinforced retroactively in response to successful litigation on behalf of disabled plaintiffs. In general, such litigation has not fared well (Colker 2005). The 2008 ADA Amendments Act was largely designed to create a statutory basis to reverse this trend, and it has had some success in doing so (Befort 2013).

Title II prohibits discrimination against disabled people by any entity receiving federal financial assistance. This title can be used to ensure that disabled people have equal access "nearly any program or activity conducted by a public entity ranging from higher education to prisons to public health care" (Colker 2005, p. 20). Indeed, as disabled people utilize such services in a disproportionately higher amount than the general population, they have benefited greatly from this part of the Act (Colker 2005, p. 126). A particularly significant court ruling regarding this title is Olmstead v. L.C., 527 U.S. 581 (1999), 
which found that "unjustified isolation is discrimination on the basis of disability under ADA Title II" (Colker 2005, p. 127). Olmstead established a precedent for justifying the removal of disabled people from segregated institutions and their integration into appropriate community settings.

Title III prohibits discrimination against disabled people in places of public accommodation. Such discrimination includes "outright exclusion, discriminatory policies and eligibility criteria, as well as broad physical barriers that impede accessibility" (Colker 2005, p. 21). The title's coverage is "broad", including entities that individuals visit on a frequent basis to enhance the quality of their lives, such as restaurants, hotels, and places of amusement and recreation (Colker 2005, p. 21). Though this Title has had a positive effect, particularly with the construction of new facilities, its effectiveness has been significantly limited by its only allowing plaintiffs injunctive relief, not monetary damages (Bagenstos 2009; Colker 2005).

These three titles make up the core of the ADA. This core has been (in general) expanded on by the ADA Amendments Act of 2008, which attempts to broaden the Act's definition of disability, with specific reference to the range of people who can qualify for reasonable accommodation in the workplace (Emens 2012). The UN Convention on the Rights of Persons with Disabilities (UNCRPD) is even more ambitious, but it has not been adopted in the U.S., though sections of it may be incorporated into future disability rights legislation (Harpur 2012).

Having outlined the basic framework of the ADA, I will now examine how this framework might apply to dying people.

\section{The Relevance of the ADA to Dying People}

As I argued above, there is little question that dying people would qualify as disabled under the ADA. The problem, however, is that while they would qualify under the ADA, the Act's key provisions have not in general been applied to them and in many cases cannot be applied to them.

This is particularly the case with Title I. Title I pertains only to employment. Though in theory dying people could experience employment discrimination, in practice that would be almost impossible to prove. The reasoning why is the opposite of why so many ADA cases have failed. The question is not whether dying people are disabled. The reality is that dying people are generally too disabled to work, regardless of any reasonable accommodation. As a result of this, Title I of the ADA would not, in general, apply to them.

Title II of the ADA is more promising. Dying people are extremely dependent on public services. Indeed, the U.S. hospice system is a public one. Medicare pays for $85.5 \%$ of hospice care (National Hospice and Palliative Care Organization 2015). Medicaid pays for the majority of nursing home care (Harrington et al. 2015). Beyond that, many dying receive Social Security, veterans benefits, and other forms of governmental assistance. There are thus many potential areas in which dying people may be discriminated against under Title II.

The Olmstead decision provides a particularly compelling precedent. Nursing homes have long been decried by the disability rights community as segregationist institutions, a description that Olmstead, to a degree, upholds. If the isolation of disabled people in nursing homes can be considered "unjustified", that would seem doubly true for terminally ill people. Nursing homes are at the very least designed for disabled people. They are not facilities for people who are terminally ill. And yet, in the U.S., they are considered the appropriate facilities for when homecare fails. Given both the segregationist bent of nursing homes, as well as their well-documented failures to provide dying people with requisite services, their continued usage might, in certain cases, be considered an abrogation of the rights of the dying as protected under the Title II of the ADA.

There is an opposite problem as well. Some dying individuals may prefer to live in the segregated environment of the nursing home, but may not be allowed entry. Such a preference should be understood in the context of the limited options available to them in U.S. society. As I have argued above, the lack of long-term care within the U.S. hospice system can make the home into an environment that is every bit as dangerous—and isolating —as the nursing home. Additionally, 
many dying individuals do not want to "burden" their families. The result can be that, in some cases, dying individuals might prefer to receive care in the nursing home, however "segregated". Olmstead would be of limited usage in such cases, as it does not create a mandate for "segregation", even if that is the individual's preference (Chambers 2009).

Title III of the ADA forces places of public accommodation to make themselves accessible. This could be immensely helpful to the dying. Due to the U.S. hospice system's basis in the home environment, terminally ill individuals depend on access to many of the kinds of businesses covered under the title. Ensuring the accessibility of these locations would be of great service to terminally ill people. The problem is that the impact of Title III has been significantly limited by its enforcement scheme. As I noted above, this scheme only allows for injunctive relief-not monetary reward-and has thus strongly disincentivized plaintiffs from seeking legal recourse (Colker 2005, p. 166). But even with a monetary reward, it would be extremely difficult for dying people to bring lawsuits due to their significant physical limitations and shortened lifespans.

Indeed, the very nature of ADA litigation arguably precludes dying people from benefitting under it. In the ADA, individuals must bring lawsuits retroactively, after a putative violation has occurred. Such an approach works against the dying. Dying individuals may themselves be too sick to pursue such lawsuits, and they are likely to die before their consummation. However, though this is to a degree true, it does not have to be an absolute barrier to reward under the ADA. A cause lawyering approach — as advocated by Nina Cohn with regard to the civil rights of elderly people - might make it possible to raise and clarify the status of the civil rights of dying people under the ADA (Kohn 2010, p. 75). As I have shown here, there may be cases in which such rights apply. Unfortunately, there will also be many in which they do not, and the retroactive nature of ADA claims will disincentivize much action on behalf of dying people.

Due to the limits of the ADA, it is necessary to develop a separate piece of legislation to protect the rights of dying people.

\section{The Need for the Rights of the Dying}

The limited applicability of the ADA to the dying can be illustrated by the decision that, above, I argued might be most promising: Olmstead v. L.C. Under the ADA, an individual may be moved from a nursing home if a more communally integrated setting exists. The problem for dying people is that, in the U.S., a dying person would not have likely arrived in a nursing home if there were a more communally integrated setting. The U.S. hospice system is based in the home. If a person is in a nursing home, it means that home care options have failed.

This does not make the segregation of the dying in nursing homes any less abominable from a disability rights perspective. However, it does limit the extent to which the ADA can end this segregation. Without an equivalent, but more integrated setting for care available, then Olmstead would not apply. Such a setting will not likely be available without dramatically changing the U.S. hospice system to include outpatient long-term care. The ADA has not proven an effective vehicle for extending such long-term care in general (Batavia and Schriner 2001; Bagenstos 2009), and it might be a particularly poor vehicle for doing so on behalf of the dying. Their long-term care needs are likely to be even more costly than those of a long-term disabled person, and courts have typically interpreted the ADA in a manner that takes such cost into account (Colker 2005).

There is other disability rights legislation that is better suited than the ADA to advance the interests of the dying. For example, the Fair Housing Act could be marshaled-in a manner similar to what Eric Carlson has argued-to make it difficult for nursing homes to reject dying patients on account of their medical needs (Carlson 2007); it might also be used to make it more difficult for assisted living facilities to involuntarily discharge dying patients when their medical needs become too extensive (Kohn 2010, p. 54).

Alternatively, recent attempts by disability advocates to legally challenge the institutional bias of Medicaid could be of assistance to dying people (Bagenstos 2009, pp. 145-48). Indeed, this institutional 
bias is even stronger at the end of life. Dying people do not just need Medicaid funding for personal assistance services; they may also need to coordinate this funding with Medicare funding for hospice. Such "dual eligibility" is theoretically possible. However, in practice, it generally only applies to Medicaid funding for nursing homes. Recently, in 2016, the State of North Carolina amended their Clinical Coverage Policy 3D to allow concurrent hospice and personal care services to be made available to dual eligible state residents (North Carolina Division of Medical Assistance 2016). Such legislation, if implemented more broadly, would be of tremendous assistance in advancing the civil rights of the dying. However, by itself, it can only be implemented on a state-by-state basis.

As an alternative to the ADA, the Rehabilitation Act of 1973 might provide a better vehicle for advancing the rights of dying people. Unlike the ADA, the Rehabilitation Act focuses on federally funded programs. Specifically, it prohibits discrimination against disabled people by programs that receive federal funding (Chamusco 2017). As such, it applies to both Medicare and Medicaid. The Rehabilitation Act could be used to impose requirements on state Medicaid programs as a condition of the receipt of federal funding. These requirements could be expanded to include a prohibition against discrimination on the basis of terminal illness. If such discrimination were defined to include, for example, access to personal care services, the Rehabilitation Act could provide a means of dramatically expanding access to long-term care amongst dying people in a manner much more efficient than a state-by-state approach.

Such an intervention could be thwarted by the way that courts have interpreted civil rights laws for disabled people. As Leslie Francis and Anita Silvers argue in an article published in this special issue of Laws, the courts have interpreted Alexander $v$. Choate-the dominant case regarding the definition of "access" in civil rights legislation for the disabled-in a manner that does not ensure that disabled people receive adequate care (Francis and Silvers 2017). On the contrary, this interpretation has argued that inadequate care in publicly funded programs is non-discriminatory so long as it is universally applied. This interpretation would likely provide a barrier to an argument that the lack of available personal care assistants is discriminatory against the dying, since this lack is relatively widespread. However, it might provide some foundation for a claim of discrimination, in circumstances in which dying people are uniquely hindered from access to such care because they are already receiving the Medicare Hospice Benefit. Regardless, Francis and Silvers have themselves reinterpreted Alexander v. Choate in a manner that collapses this access/content distinction and works toward a more robust conception of "meaningful access." Doing so has the potential to authorize significantly broader anti-discrimination legislation for the dying.

Given the difficulty of such an approach, it might be better to begin with the more limited claim that section 1557 of the Affordable Care Act (ACA) include discrimination on the basis of terminal illness. Section 1557 creates a new civil right to health care (Watson 2011). It does so by extending anti-discrimination protection to Medicare, Medicaid, health insurance marketplaces, and the plans offered by insurers that participate in those marketplaces. If Section 1557 was extended to the terminally ill, it might be used to ameliorate discrimination that keeps terminally ill individuals on hospice from access to Medicaid-funded personal assistance services. Alternatively, it could eliminate barriers to hospice access amongst dying people without familial caregivers. As 12\% of U.S. hospices do not accept dying people in such circumstances, such discrimination is significant (Aldridge Carlson et al. 2012). Similarly, the same study found that $78 \%$ of U.S. hospices had enrollment policies that might restrict care for patients with high-cost medical needs (Aldridge Carlson et al. 2012). Extending Section 1557 protection to dying people might provide a means of combatting such discrimination in access. Even without such an extension, focusing on the end of life can, as the above examples show, highlight other potential forms of discrimination on the basis of factors such as race, gender, and socio-economic status.

Such measures are potentially very important. However, they may not be enough, by themselves, to ameliorate the unjustified segregation of dying Americans in the U.S. hospice system. Such segregation is but one example of the kind of discrimination experienced by the dying. A disability rights framework provides a theoretical foundation for recognizing this discrimination. However, 
existing disability rights legislation does not provide suitable civil rights grounds for either it recognition, nor its amelioration. It is thus necessary to move beyond the existing legislation to create civil rights legislation for dying people.

It is beyond the scope of this paper to provide a model for such legislation. However, its theoretical framework would be drawn from the ADA: the description of dying as a condition that is not primarily medical but socio-political, the identification of discrimination against terminally ill people, and the move from a "social benefits" approach to rights. More specifically, terminally ill people should be considered entitled to long-standing disability rights, such as the right to the least restrictive environment and the right to self-determination (Dhanda 2006; Mégret 2008; Weber 2004). In both the cases of Simon and Mary, which I describe above, I would argue that such disability rights were violated, even if such a violation could not be (easily) perceived or remedied within the framework of the ADA. In this sense, the rights of dying people should be understood to be consistent with-and an extension of-disability rights. And it is, I believe, in the interests of disability rights advocates to support them.

\section{Conclusions}

In the section above, I argued that the ADA would be of limited direct utility to dying people. This is true. However, this should not diminish its enormous indirect utility. Indeed, the ADA, as I have also argued, provides an essential theoretical basis for the recognition of the civil rights of terminally ill people. More than that, it is of immense practical benefit to terminally ill people. The creation of a more accessible society, through the ADA's Title II and III, benefits dying patients in home care, and has some potential—through a reinterpretation of Olmstead — to give them significantly more autonomy over where they spend their final months of life. Even Title I is of indirect benefit. Most people are disabled before they are dying, and increased employment during that time likely augments both the social and economic capital that they will have available to them when they come to life's end. Even with its limitations, the ADA thus is of significant benefit to dying people.

Similarly, the establishment of civil rights for dying people, while not directly applicable to the long-term disabled, would likely benefit them. Such rights will be different than disability rights. However, they could be different in a way that fills some of the existing gaps in the ADA. For example, most dying people cannot work. This makes ADA Title I not applicable to them. But Title I has been of limited utility in boosting employment amongst disabled people. The Urban Institute has found that high unemployment among disabled people is not primarily due to workplace discrimination. Rather, it can be attributed to other factors, including social isolation, family responsibilities, a lack of transportation, a lack of training, and a fear of the loss of benefits (Loprest and Maag 2001, cited in (Colker 2005, p. 70)). Many of these factors also impact dying people. If crafted appropriately, civil rights legislation for the dying might address them and, by doing so, bring additional help to disabled people.

Such legislation could include, for example, a greater availability of long-term care for dying people. But advocates for the dying could also take what Samuel Bagenstos has termed a more "universalist" approach: establishing a general political right to long-term care or perhaps just palliative care. Indeed, as suggested to me by one of this article's anonymous reviewers, the lack of long-term care in the MHB can itself be considered symptomatic of (and perhaps secondary to) the limits that Medicare places on non-skilled services in general. This is a question of legal and political strategy that is beyond the purview of this article. My point here is that either approach would be beneficial to disabled people: indirectly, the provision of long-term care to the dying could create the grounds for the statutory or legislative expansion of long-term care for disabled people; or directly, a universalist approach would provide coverage to both disabled people and people who are dying.

There are many such areas of overlap: accessible housing, public transportation, access to palliative medicine, the reformulation—and perhaps abolition —of nursing homes, personal attendants, and meal delivery services, to name a few. Progress for dying people in these and other areas will be 
closely related to, and at times indistinguishable from, progress for disabled people. And, ultimately, such shared progress is more likely to happen if advocates for dying people and disability rights advocates understand their interests as aligned. Such an alliance will expand the political capital of both groups. It will also lead to more sophisticated and creative interplay of how to advance disability and dying rights.

Conflicts of Interest: The author declares no conflict of interest.

\section{References and Notes}

Abel, Emily K. 2013. The Inevitable Hour: A History of Caring for Dying Patients in America. Baltimore: JHU Press.

Abel, Emily K. 2017. Living in Death's Shadow: Family Experiences of Terminal Care and Irreplaceable Loss. Baltimore: JHU Press.

Aldridge, Melissa D., and Amy S. Kelley. 2015. The Myth Regarding the High Cost of End-of-Life Care. American Journal of Public Health 105: 2411-15. [CrossRef] [PubMed]

Aldridge Carlson, Melissa D., Colleen L. Barry, Emily J. Cherlin, Ruth McCorkle, and Elizabeth H. Bradley. 2012. Hospices' enrollment policies may contribute to underuse of hospice care in the United States. Health Affairs 31: 2690-98. [CrossRef] [PubMed]

Aragon, Katherine, Kenneth Covinsky, Yinghui Miao, W. John Boscardin, Lynn Flint, and Alexander K. Smith. 2012. Use of the Medicare posthospitalization skilled nursing benefit in the last 6 months of life. Archives of Internal Medicine 172: 1573-79. [CrossRef] [PubMed]

Bagenstos, Samuel R. 2009. Law and the Contradictions of the Disability Rights Movement. New Haven: Yale University Press. Batavia, Andrew I. 1997. Disability and physician-assisted suicide. New England Journal of Medicine 336: 1671-73. [CrossRef] [PubMed]

Batavia, Andrew I., and Kay Schriner. 2001. The Americans with Disabilities Act as engine of social change: Models of disability and the potential of a civil rights approach. Policy Studies Journal 29: 690-702. [CrossRef]

Befort, Stephen F. 2013. An Empirical Examination of Case Outcomes under the ADA Amendments Act. Washington and Lee Law Review 70: 2027.

Behuniak, Susan M. 2011. Death with "dignity". Politics and the Life Sciences 30: 17-32. [PubMed]

Braswell, Harold. 2018. Putting the "right to die" in its place: Physician-assisted suicide: Disability Rights and Physician-Assisted Suicide in the Context of US End-of-Life Care. Studies in Law, Politics, and Society. Forthcoming. Byock, Ira. 2012. The Best Care Possible: A Physician's Quest to Transform Care Through the End of Life. New York: Avery.

Carlson, Eric M. 2007. Disability Discrimination in Long-Term Care: Using the Fair Housing Act to Prevent Illegal Screening in Admissions to Nursing Homes and Assisted Living Facilities. Notre Dame Journal of Law, Ethics E Public Policy 21: 363-404.

Chambers, Megan. 2009. Integration as Discrimination against People with Disabilities-Olmstead's Test Shouldn't Work Both Ways. California Law Review 46: 177-209.

Chamusco, Binaca G. 2017. Revitalizing the Law That Preceded the Movement: Associational Discrimination and the Rehabilitation Act of 1973. The University of Chicago Law Review 84: 1285.

Colker, Ruth. 2005. The Disability Pendulum: The First Decade of the Americans with Disabilities Act. New York: NYU Press.

Colker, Ruth. 2008. When is Separate Unequal? A Disability Perspective. Cambridge: Cambridge University Press.

Davis, Lennard J. 2013. The End of Normal. Ann Arbor: University of Michigan Press.

Dhanda, Amtia. 2006. Legal capacity in the disability rights convention: Stranglehold of the past or lodestar for the future. Syracuse Journal of International Law and Commerce 34: 429-62.

Dowbiggin, Ian. 2007. A Concise History of Euthanasia: Life, Death, God, and Medicine. Lanham: Rowman \& Littlefield.

Emens, Elizabeth F. 2012. Disabling attitudes: US disability law and the ADA amendments act. The American Journal of Comparative Law 60: 205-34. [CrossRef]

Francis, Leslie, and Anita Silvers. 2017. Reading Alexander V. Choate Rightly: Now is the Time. Laws 6: 17. [CrossRef]

Gill, Carol. 1998. The False Autonomy of Forced Choice: Rationalizing Suicide for Persons with Disabilities. In Contemporary Perspectives on Rational Suicide. Edited by James L. Werth. Philadelphia: Taylor \& Francis, pp. 171-80. 
Gill, Carol. 2010. No, we don't think our doctors are out to get us: Responding to the straw man distortions of disability rights arguments against assisted suicide. Disability and Health Journal 3: 31-38. [CrossRef] [PubMed]

Hacker, Jacob S. 2002. The Divided Welfare State: The Battle over Public and Private Social Benefits in the United States. Cambridge: Cambridge University Press.

Halabi, Sam. 2014. Selling Hospice. The Journal of Law, Medicine E Ethics 42: 442-54.

Harpur, Paul. 2012. Embracing the new disability rights paradigm: The importance of the Convention on the Rights of Persons with Disabilities. Disability E Society 27: 1-14.

Harrington, Charlene, Helen Carrillo, and Rachel Garfield. 2015. Nursing Facilities, Staffing, Residents and Facility Deficiencies, 2009 through 2014. Kaiser Family Foundation Report. Available online: http:/ / files.kff.org/ attachment/REPORT-Nursing-Facilities-Staffing-Residents-and-Facility-Deficiencies-2009-2015 (accessed on 12 December 2017).

Heyer, Katharina. 2011. Rejecting rights: The disability critique of physician assisted suicide. In Special Issue Social Movements/Legal Possibilities. Bingley: Emerald Group Publishing Limited, pp. 77-112.

Hoyer, Thomas. 1998. A history of the Medicare hospice benefit. Hospice Journal 13: 61-70. [CrossRef] [PubMed] Institute of Medicine. 2014. Dying in America: Improving Quality and Honoring Individual Preferences Near the End of Life. Available online: http://www.nationalacademies.org/hmd/Reports/2014/Dying-InAmerica-Improving-Quality-and-Honoring-Individual-Preferences-Near-the-End-of-Life.aspx (accessed on 1 September 2017).

Jennings, Bruce. 2013. Solidarity, Mortality: The Tolling Bell of Civic Palliative Care. In Our Changing Journey to the End: Reshaping Death, Dying, and Grief in America [2 volumes]: Reshaping Death, Dying, and Grief in America. Edited by Christina Staudt and J. Harold Ellens. Westport: Praeger, vol. 2, pp. 271-90.

Johnson, Harriet McBryde. 2003. The disability gulag. New York Times Magazine 23: 58-64.

Kidder, David. 1992. The effects of hospice coverage on Medicare expenditures. Health Services Research 27: 195-217. [PubMed]

Kohn, Nina A. 2010. The Lawyer's Role in Fostering an Elder Rights Movement. William Mitchell Law Review 37: 49.

Linda H. Krieger, ed. 2003. Backlash against the ADA: Reinterpreting Disability Rights. Ann Arbor: University of Michigan Press.

Levitsky, Sandra R. 2014. Caring for Our Own: Why There Is No Political Demand for New American Social Welfare Rights. Oxford: Oxford University Press.

Longmore, Paul K. 2005. Policy, Prejudice, and Reality Two Case Studies of Physician-Assisted Suicide. Journal of Disability Policy Studies 16: 38-45. [CrossRef]

Lunney, June R., Joanne Lynn, Daniel J. Foley, Steven Lipson, and Jack M. Guralnik. 2003. Patterns of functional decline at the end of life. JAMA 289: 2387-92. [CrossRef] [PubMed]

Lynn, Joanne, Frank Harrell, Felicia Cohn, and Mary Hamel. 1996. Defining the terminally ill: Insights from support. Duquesne Law Review 35: 311-36. [PubMed]

Mégret, Frédéric. 2008. The disabilities convention: Human rights of persons with disabilities or disability rights? Human Rights Quarterly 30: 494-516.

Mor, Vincent, and David Kidder. 1985. Cost savings in hospice: final results of the National Hospice Study. Health Services Research 20: 407-22. [PubMed]

National Hospice and Palliative Care Organization. 2012. NHPCO Facts and Figures: Hospice Care in America. Available online: https:/ / www.nhpco.org/sites/default/files/public/newsline/2012/NL_March_12.pdf (accessed on 12 December 2017).

National Hospice and Palliative Care Organization. 2015. The Medicare Hospice Benefit. Available online: https://www.nhpco.org/sites/default/files/public/communications/Outreach/The_Medicare_ Hospice_Benefit.pdf (accessed on 12 December 2017).

Neumann, Ann. 2016. The Good Death. Boston: Beacon Press.

North Carolina Division of Medical Assistance. 2016. Medicaid and Health Choice, Clinical Coverage Policy No. 3D. Available online: https:/ / files.nc.gov/ncdma/documents/files/3D_2.pdf (accessed on 12 December 2017).

Paradis, Lenora Finn, and Scott B. Cummings. 1986. The evolution of hospice in America toward organizational homogeneity. Journal of Health and Social Behavior 27: 370-86. [CrossRef] [PubMed]

Perry, Joshua E., and Robert C. Stone. 2011. In the Business of Dying: Questioning the Commercialization of Hospice. The Journal of Law, Medicine E Ethics 39: 224-34. 
Rabow, Michael W., Joshua M. Hauser, and Jocelia Adams. 2004. Supporting family caregivers at the end of life: They don't know what they don't know. JAMA 291: 483-91. [CrossRef] [PubMed]

Sampson, Robert J. 2012. Great American City: Chicago and the Enduring Neighborhood Effect. Chicago: University of Chicago Press.

Schriner, Kay, and Richard Scotch. 2003. The ADA and the Meaning of Disability. In Backlash against the ADA: Reinterpreting Disability Rights. Edited by Linda Hamilton Krieger. Ann Arbor: University of Michigan Press, pp. 164-88.

Scotch, Richard. 2001. From Good Will to Civil Rights: Transforming Federal Disability Policy. Philadelphia: Temple University Press.

Shakespeare, Tom. 2013. The Social Model of Disability. In The Disability Studies Reader. Edited by L. Davis. London: Routledge, pp. 214-21.

Stevenson, David G., and Jeffrey S. Bramson. 2009. Hospice care in the nursing home setting: A review of the literature. Journal of Pain and Symptom Management 38: 440-51. [CrossRef] [PubMed]

The Connecticut Hospice. 1982. Administrator Testifies on Hospice Legislation. In The Connecticut Hospice Newsletter, vol. 8, No.1. Box 6, Folder 74, Florence and Henry Wald Papers, Sterling Memorial Library, Yale University.

Watson, Sidney D. 2011. Section 1557 of the Affordable Care Act: Civil Rights, Health Reform, Race, and Equity. Howard LJ 55: 855.

Weber, Mark C. 2004. Home and community-based services, Olmstead, and positive rights: A preliminary discussion. Wake Forest Law Review 39: 2692-90.

Wyatt, Karen. 2015. Social Model Hospice Homes May Revolutionize End-of-Life Care in the U.S. Huffington Post. Available online: http:/ / www.huffingtonpost.com/karen-m-wyatt-md/social-model-hospice_b_7641916. html (accessed on12 December 2017).

(C) 2017 by the author. Licensee MDPI, Basel, Switzerland. This article is an open access article distributed under the terms and conditions of the Creative Commons Attribution (CC BY) license (http:/ / creativecommons.org/licenses/by/4.0/). 